\title{
GENETIC DIVERSITY AND POPULATION STRUCTURE OF FARMERS' MAIZE VARIETIES (ZEA MAYS L.) FROM THREE SELECTED STATES IN NIGERIA USING SSR MARKERS AND THEIR RELATIONSHIP WITH STANDARD HYBRIDS
}

\author{
Adeyemo, O. A. ${ }^{1}$ and Omidiji, O. ${ }^{1}$ \\ Department of Cell Biology and Genetics, University of Lagos, Akoka, Lagos, Nigeria \\ *E-mail address of the corresponding author: aoadeyemo@unilag.edu.ng; adeyemona@gmail.com \\ (Received: $2^{\text {nd }}$ February, 2019; Accepted: $15^{\text {th }}$ April, 2019)
}

\section{ABSTRACT}

\begin{abstract}
Maize (Zea mays L.) is an economically important tropical crop cultivated by farmers in Nigeria. In this study, genetic diversity and population structure were assessed in a set of 19 maize varieties, including most commonly grown maize varieties by farmers in Edo, Ekiti and Kwara states in Nigeria and newly developed hybrids in International Institute of Tropical Agriculture (IITA). The accessions were assayed with 20 SSR flanking markers of previously mapped quantitative trait loci linked with the oil and protein or oil/protein contents. All SSR markers were polymorphic with the mean polymorphism information content value of 0.75 . Based on the SSR genotyping data, a total of 183 alleles, ranging from 3 to 18 averaging 9.15 were detected. A moderately high number of unique alleles was present in 3 farmers' varieties (EK04, EK06, KW11) and a hybrid (LW18). The 19 maize varieties were separated into two main groups: 5 varieties clustered in group I; 13 maize varieties clustered in group II but subdivided into two subgroups; The subgroup 1 included four farmers' varieties from Kwara (2) and Ekiti (2) and the remaining 2 were from the IITA while three hybrids (LW17, LW18, and LW19), and four farmers' varieties from Kwara clustered in subgroup 2 in the dendrogram. The one landrace from Ekiti state stood alone in the dendrogram and was distinct from the other farmers' varieties and the newly developed hybrids. The result from the factorial analysis was consistent with the dendrogram and grouping based on states of the collection of farmers' varieties and the newly developed hybrid may be considered substantial. The result of the STRUCTURE analysis classified the 19 varieties as an admixture, indicating one population which was not in accordance with the dendrogram and factorial analyses. The study using SSR analysis has revealed the genetic variation among the farmers' varieties and their genetic relationship with the IITA maize hybrids. The information obtained from the study may form the basis for maize breeding and conservation programs in the future.
\end{abstract}

Key Words: Maize, Genetic diversity, Population structure, SSR markers

\section{INTRODUCTION}

Maize (Zea mays L.) is an economically important tropical crop cultivated by farmers for food and maize by-products for animal feed in the subSaharan Africa countries. In Nigeria, local farmers grow more of improved maize varieties than the maize landraces that are locally adapted (Salami et al., 2007). Maize breeding program in the International Institute of Tropical Agriculture (IITA) has developed and released improved highyielding and disease-resistant maize varieties that are adaptable to diverse agro-ecological zones, raising maize production in Nigeria (Abdulmalik et al., 2017). Farmers have always had access to affordable quality seeds of new and improved maize varieties which may lead to narrowing of the genetic diversity of maize landraces in the custody of the farmers. The lack of protection of genetic resources of the original maize landraces is also a major contributing factor leading to loss of its genetic variability. Moreover, local storage of seeds of maize landraces by farmers are common practices but have sometimes caused local extinction of maize landraces.

Study of genetic diversity and structure among the diverse array of farmers' varieties and IITA hybrids is very essential in breeding programs, conservation and utilization of diverse genetic resources for cultivar improvement and protection. For use in the conservation of genetic resources, the local germplasm can be effectively protected and prevented from loss of genetic diversity. Moreover, genetic resources for breeding will help establish desirable genes of key traits (e.g. oil and protein contents) from some landraces which can be introgressed into inbred lines for the improvement of the maize crop. 
Molecular marker-based characterisation has potentials to accurately reveal genetic diversity and population structure among the farmers' maize varieties and IITA hybrids. Microsatellites (simple sequence repeats, SSR) are widely used to evaluate genetic diversity and population structure based on their multiallelic nature; they can produce many alleles per locus, abundance and are repeatable (Warburton et al., 2008). SSR markers have been applied to characterize the genetic relationships of yellow adapted tropical maize germplasm from IITA breeding programs in Nigeria (Adeyemo and Omidiji, 2014). Also, a number of previous studies have reported the genetic diversity, genetic relationship and population structure of diverse maize inbred lines, breeding materials and maize landraces from the different maize germplasm and breeding programs based on SSR data (Inghelandt et al., 2010; Zhi-zhai et al., 2010; Semagn et al., 2014; Bedoya et al., 2017).

In addition, SSR markers have also been used to investigate the molecular basis of quantitative traits to facilitate the development of genetic maps and to map chromosomal regions that affect quantitative trait loci (QTLs) for many different maize population (Mangolin et al., 2004; Zhang et al., 2007; Yang et al., 2016). Such mapped QTLs linked SSR markers have been successfully used to assess the genetic diversity among the maize landraces and how their genetic variation is related to some hybrid lines (Adeyemo et al., 2018). The genetic diversity of farmers' maize varieties has been carried out in communities of the western highlands of Guatemala (van Etten et al., 2008). Also, Lia et al. (2009) studied the genetic diversity and population structure in maize landraces cultivated by traditional farmers in mid to high altitude locations of Northwestern Argentina.

The farmers determine which varieties are mainly cultivated under the specific agro-environmental condition in some towns/villages in Edo, Ekiti and Kwara, states in Nigeria. In recent years, some of the improved maize varieties are well appreciated by farmers due to the peculiar grain characteristics (usage, sowing date, storability, etc.) and agronomic characteristics. Presently, the current genetic variability and structure at the molecular level in the farmers' maize varieties and the recently improved varieties by IITA have not been studied. This information would be useful for breeding improved maize genotypes and for genetic resource management in gene banks. Therefore, this study was conducted to assess the extent of genetic diversity and the population structure of the current farmers' maize varieties and the IITA hybrids using SSR markers.

\section{MATERIALS AND METHODS}

\section{Maize Sample Collections, Study Areas and Plant Materials used in the Study}

The seeds of farmers' varieties were randomly collected in April 2018 directly from the indigenous farmers at different farms in the villages/towns of Edo, Ekiti and Kwara states of Nigeria visited during a collection trip. Farms were selected based on where traditional agriculture is the main occupation of the people. The geographical distribution of where each of the farmers' varieties was collected is shown in figure 1 and some of the maize varieties collected are depicted (Plate 1). We collected a total of 22 maize samples, some in cobs and some in seed samples from conserved seed lots. Maize samples from the 3 states were selected according to variation in the seed morphological traits (sizes and colours, from light purple to creamy-white to shiny white to deep orange to glowing orange). Seed germination was very poor for some of the varieties. In addition to these farmers' varieties, the seeds of newly improved maize which are representatives of standard hybrids and well adapted to the southwest tropical environmental conditions were kindly provided by a maize breeder in IITA, and were included in this study. A total of nineteen diverse maize genotypes consisting of 14 farmers' varieties (traditional landraces and released improved cultivars; 3 from Edo, 5 from Ekiti and 6 from Kwara and 5 new improved maize hybrids were used in this study (Table 1). 
Adeyemo and Omidiji: Genetic Diversity and Population Structure of Farmers' Maize

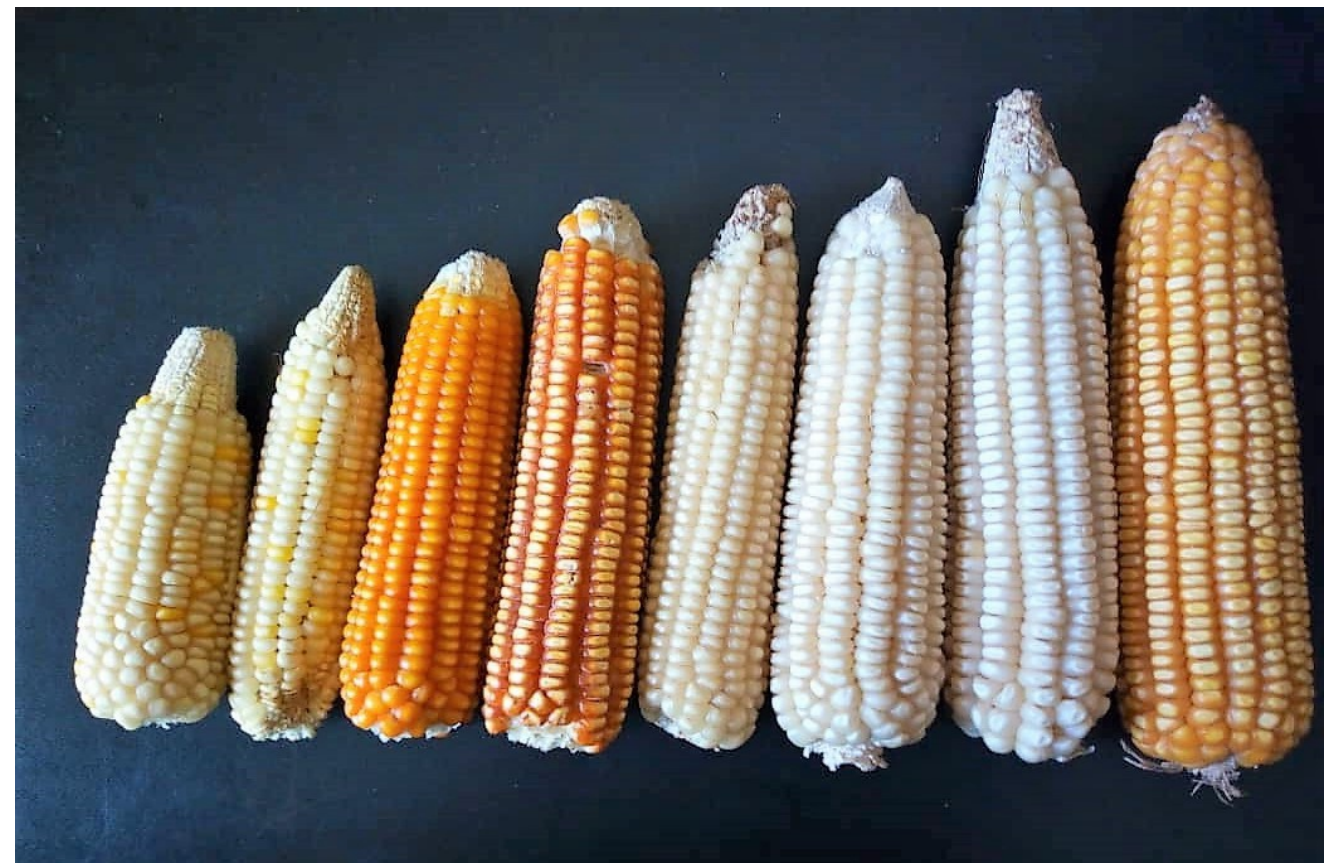

Plate 1: Picture showing the Morphological Diversity of Maize Genotypes collected in Edo, Ekiti and Kwara States

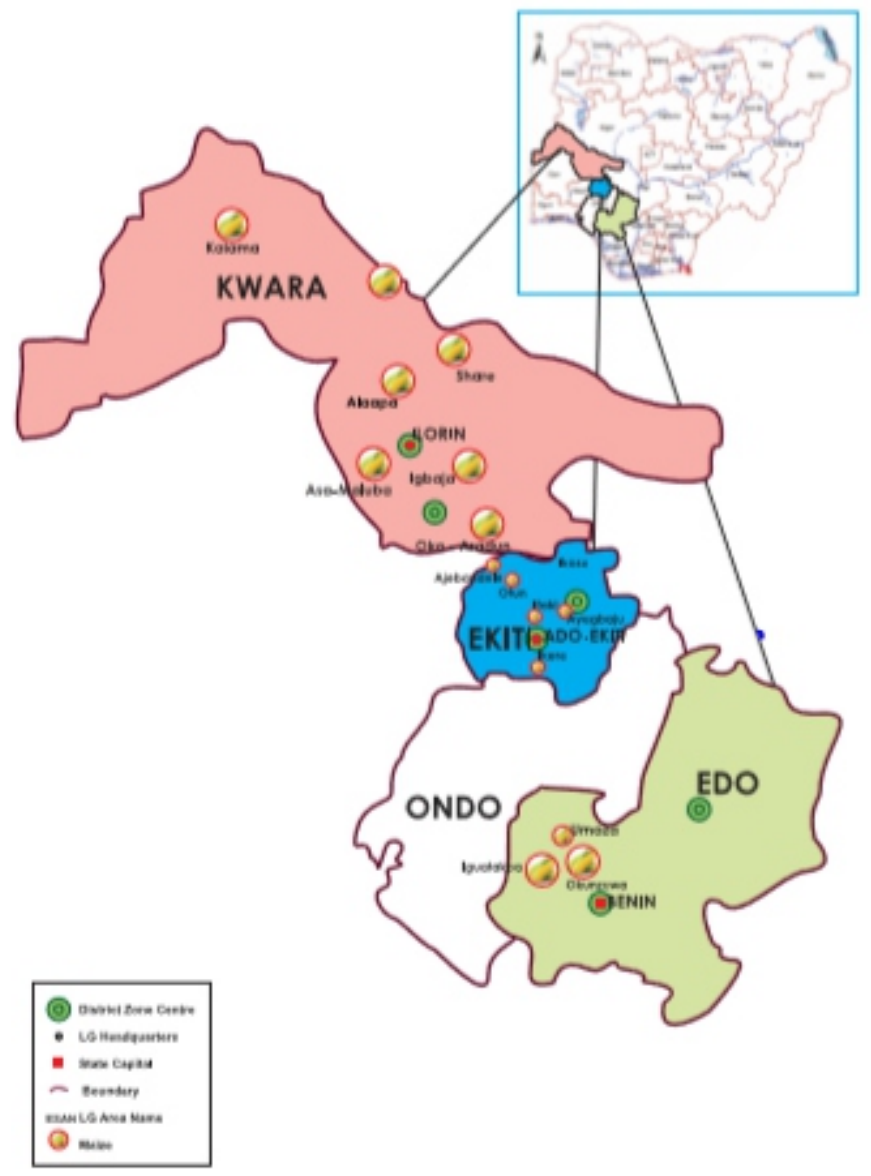

Figure 1: A Map of Edo, Ekiti and Kwara States showing the Location of Towns where Maize Samples were collected 
Adeyemo and Omidiji: Genetic Diversity and Population Structure of Farmers' Maize

Table 1: Details of Maize Varieties used for the Analysis of Genetic Diversity Study

\begin{tabular}{lll}
\hline Codes & Collection sites (Places \& States) & Kernel colour \\
\hline ED01 & UMAZA (Edo) & White (shiny) \\
ED02 & IGUATAKPA (Edo) & Yellow \\
ED03 & OKUNZUWA (Edo) & Yellow \\
EK04 & OTUN-EKITI (Ekiti) & White \\
EK05 & OTUN-EKITI (Ekiti) & White \\
EK06 & IKERE-EKITI ( Ekiti) & White (landrace) \\
EK07 & IFAKI- EKITI (Ekiti) & Yellow \\
EK08 & IKOSU-EKITI (Ekiti) & Yellow \\
KW09 & KAIMA (Kwara) & White \& purple (landrace) \\
KW10 & APA-OLA (Kwara) & White (landrace) \\
KW11 & APA-OLA (Kwara) & Yellow \\
KW12 & APA-OLA (Kwara) & Yellow \\
KW13 & ASA-MALUBA (Kwara) & Yellow \\
KW14 & ALA-APA (Kwara) & Yellow \\
LW15 & LW1701-1 (IITA, Oyo) & White \\
LW16 & LW1701-3 (IITA, Oyo) & White \\
LW17 & LW1701-4 (IITA, Oyo) & White \\
LW18 & LW1701-5 (IITA, Oyo) & White \\
LW19 & LW1701-6 (IITA, Oyo) & White \\
\hline
\end{tabular}

\section{Simple Sequence Repeat Loci}

Twenty simple sequence repeat (SSR) markers were used for genotyping (Table 2). These SSR markers were selected on the basis of the ten maize chromosome groups for fair coverage of the genome. All SSR loci were markers or flanking markers of previously mapped QTLs and located in chromosomes for the oil and protein or oil/protein contents (Mangolin et al., 2004;
Zhang et al., 2007; Yang et al., 2016). The SSRs assayed, including bin locations, information on genetic map position in centiMorgan (cM), each QTL detected for oil and protein content and references, are listed in table 2 . The sequences for primer pairs were obtained from the Maize Genetics and Genomics Database (Maize GDB) (http://www.maizegdb.org) and synthesized by Inqaba Biotec West Africa Ltd., South Africa. 
Table 2: Characteristics of SSR Markers Linked with QTL used in the Study

\begin{tabular}{|c|c|c|c|c|c|}
\hline $\mathrm{S}$ No & SSR markers & Chr & Position $(\mathrm{cM})^{\mathrm{a}}$ & QTL names & Reference \\
\hline 1 & bnlg108 & 2 & 76 & oilc2 & Zhang et al., 2007 \\
\hline 2 & phi096 & 4 & 36 & oilc4-1 & Zhang et al., 2007 \\
\hline 3 & umc2319 & 6 & 95 & oilc6 & Zhang et al., 2007 \\
\hline 4 & umc2236 & 1 & 296.25 & qOIL01-01 & Yang et al., 2016 \\
\hline 5 & umc1072 & 5 & 210.8 & qOIL05-01 & Yang et al., 2016 \\
\hline 6 & umc1134 & 7 & 149.21 & qOIL07-01 & Yang et al., 2016 \\
\hline 7 & umc2043 & 10 & 134.82 & qOIL10-01 & Yang et al., 2016 \\
\hline 8 & umc1133 & 06L & 55.31 & koc6c & Mangolin et al., 2004 \\
\hline 9 & bnlg1700 & $05 \mathrm{~L}$ & 129.19 & koc5a & Mangolin et al., 2004 \\
\hline 10 & umc1433 & 7 & 58 & proc 7 & Zhang et al., 2007 \\
\hline 11 & umc1562 & 8 & 142 & proc8 & Zhang et al., 2007 \\
\hline 12 & umc2119 & 9 & 86 & proc9 & Zhang et al., 2007 \\
\hline 13 & umc1771 & 9 & 86 & proc9 & Zhang et al., 2007 \\
\hline 14 & umc1421 & 1 & 285.47 & qPRO01-01 & Yang et al., 2016 \\
\hline 15 & bnlg1496 & 3 & 221.48 & qPRO03-01 & Yang et al., 2016 \\
\hline 16 & umc1058 & 4 & 240.6 & $\begin{array}{l}\text { qPRO04-02 } \\
\text { qPRO05- }\end{array}$ & Yang et al., 2016 \\
\hline 17 & umc1019 & 5 & 210.8 & $\begin{array}{l}\text { 01/qOIL05-02 } \\
\text { qPRO05- }\end{array}$ & Yang et al., 2016 \\
\hline 18 & umc2038 & 5 & 210.8 & $\begin{array}{l}\text { 01/qOIL05-02 } \\
\text { qPRO06- }\end{array}$ & Yang et al., 2016 \\
\hline 19 & umc2313 & 6 & 86.23 & $\begin{array}{l}\text { 01/qOIL06-01 } \\
\text { qPRO06- }\end{array}$ & Yang et al., 2016 \\
\hline 20 & umc1595 & 6 & 86.23 & 01/qOIL06-01 & Yang et al., 2016 \\
\hline
\end{tabular}

Chromosome (Chr); Quantitative Trait Loci (QTLs)

${ }^{\mathrm{a}}$ Estimate position of QTL Relative to the SSR in the chromosome

QTLs associated with the kernel oil content (oilc, qOIL/koc)

QTLs associated with the kernel protein content (Proc/qPRO)

QTLs associated with both the kernel protein and oil contents (qPRO0601/qOIL06-01)

DNA Extraction, PCR and Polyacrylamide Electrophoresis

Seedlings were grown in plastic pots kept in the greenhouse for about 2 weeks. Fresh young leaf tissues of 8 plants per genotype were bulked and ground to fine powder using liquid nitrogen. Genomic DNA was extracted following the standard cetyltrimethylammonium bromide (CTAB) extraction protocol (Doyle and Doyle, 1987). Two volumes of cold absolute ethanol were added to the supernatant to precipitate the DNA. DNA pellets were air dried at room temperature, and later re-suspended with 100 to 200 ultrapure water for storage at $-20{ }^{\circ} \mathrm{C}$. Quality of the extracted DNA was checked on 1\% agarose gel and quantity was estimated using a NanoDrop spectrophotometer (NanoDrop Technologies, Wilmington, Delaware, USA).

Polymerase Chain Reaction (PCR) conditions for each of the 20 SSR markers were optimized using the Touchdown program and were used for further analysis on the 19 genotypes. PCR mixture contained $2.5 \mu \mathrm{l} 10 \times$ PCR buffer, $1.0 \mu \mathrm{l}$ $5 \mathrm{pMol}$ each of forward and reverse primers, $1.5 \mu \mathrm{l}$ $50 \mathrm{mM} \mathrm{MgCl}_{2}, 2.0 \mu \mathrm{l} 2.5 \mathrm{mM}$ dNTPs, $0.15 \mu \mathrm{l} 5 \mathrm{u} / \mu \mathrm{l}$ Taq polymerase, $2.0 \mu \mathrm{l} 100 \mathrm{ng} / \mu \mathrm{l} \mathrm{DNA}$, and 13.85 $\mu \mathrm{l}$ with $\mathrm{ddH}_{2} 0$ made up to $25 \mu \mathrm{l}$ total volume. The touchdown PCR cycling programs were performed for each SSR primer pair separately, using a thermal cycler (ABI Thermocycler GeneAmp, 9700). The protocol followed was 94 ${ }^{\circ} \mathrm{C}$ for 5 min, $94^{\circ} \mathrm{C}$ for $15 \mathrm{~s}, 9$ cycles at $94^{\circ} \mathrm{C}$ for 15 $\mathrm{s}$, melting temperature $\left(\mathrm{T}_{\mathrm{m}}\right)$ for $20 \mathrm{~s}, 72^{\circ} \mathrm{C}$ for $30 \mathrm{~s}$, and in the first 35 cycles the annealing temperature was reduced by $1{ }^{\circ} \mathrm{C}$ per cycle from 65 to $55^{\circ} \mathrm{C}$, the last 20 cycles were run at a constant $\mathrm{T}_{\mathrm{m}} 55^{\circ} \mathrm{C}$, followed by $72{ }^{\circ} \mathrm{C}$ for $7 \mathrm{~min}$ and a final extension of $10 \mathrm{~min}$ at $72{ }^{\circ} \mathrm{C}$. The PCR products were separated using $6 \%(\mathrm{w} / \mathrm{v})$ non-denaturing polyacrylamide gel electrophoresis in $1 \times \mathrm{TBE}$ buffer. A SafeView ${ }^{\text {TM }}$ DNA stains (Applied 
Biological Materials Inc., Richmond BC, Canada) procedure was used to reveal the amplicons after the electrophoresis. The SSRs were scored as dominant markers: the presence of a band was recorded as " 1 " and absence of the bands as " 0 " for all maize genotypes used for data analysis.

\section{Analysis of Genetic Diversity and Population Structure}

Alleles number per locus (A), expected heterozygosity (He) and polymorphism information content (PIC) values were performed for all the SSR markers using GenAlEx 6.5 software (Peakall and Smouse, 2006). The Rogers distance (Rogers, 1972) was computed, using NTSYS-pc software with 1000 bootstrap repetitions, which was used for cluster analysis. A dendrogram was constructed based on the unweighted pair group method using arithmetic average (UPGMA) algorithm using the NTSYSpc software (Numerical Taxonomy and Multivariate Analysis system), version 2.11 (Rohlf, 1993). The genetic distance matrix was further used to construct a factorial analysis to assess the molecular diversity in the maize genotypes using the Darwin 6.0 statistical software (Perrier and Jacquemoud-Collet, 2006). To infer the genetic population structure of the 19 maize lines using SSR markers, the admixture model-based program STRUCTURE version 2.2.4 was used (Pritchard et al., 2000). The admixture model was used to estimate a mixed group by using correlated allele frequencies between populations as described by Falush et al. (2003). The optimum number of subpopulations was calculated based on the recommendation of Evanno et al. (2005) by defining the values for $K=2$ to $K=10$ with a burn length of 10,000 and a run length of 100,000 each in 10 runs. The results were uploaded in a Zip file to the STRUCTURE harvester software v.0.6.92 (Earl and Von Holdt, 2012) for finding the $\Delta \mathrm{K}$. The $\mathrm{K}$ value was determined by the $\log$ probability of data $[(\operatorname{Ln} \mathrm{P}(\mathrm{D})]$ based on the rate of change in $\operatorname{Ln} P(D)$ between successive $K$.

\section{RESULTS}

\section{Allelic Variation of the SSR Markers}

The twenty SSR markers were polymorphic and 183 polymorphic alleles among the nineteen maize genotypes were produced (Figure 2). The mean number of alleles per SSR locus was 9.15, varying from 3 (umc1595) to 18 (umc2313) for each marker (Table 3). The polymorphism information content (PIC) values ranging from 0.90 for umc 2313 to 0.43 for umc1595 with an average of 0.75 (Table 3), giving the relative informativeness of each SSR marker in this study which showed high genetic diversity among the maize genotypes. Overall, 95\% of the SSR markers have PIC greater than 0.5. The results further showed that the expected heterozygosity (He) varied from 0.49 (umc1595) to 0.92 (umc2313), with a mean of 0.78 across the 20 SSR loci. The most polymorphic loci were umc2313 (18 alleles), bnlg1700 (13 alleles), and umc1058 (12 alleles) which are associated with QTLs linked to both kernel oil and protein content, oil and protein contents respectively (Tables 2 and 3). Out of 20 SSR markers, 18 SSR loci in the analysed genotypes detected a set of 48 unique alleles varying from 1 to 6 among 16 genotypes (Figure 3). The lines with 6 unique alleles were 3 farmers' varieties (EK04, EK06, KW11) while a hybrid (LW18) had 7 unique alleles (Figure 3). The number of SSR markers based on QTL type, average, minimum, maximum number of alleles among 19 maize genotypes are presented in table 4. Finally, the measure for diversity within the three states and IITA hybrids based on 20 SSR loci were obtained (Table 5). 
Table 3: SSR Variations in the Diversity Analysis

\begin{tabular}{lllll}
\hline S No & SSR markers & A & PIC value & He \\
\hline 1 & bnlg108 & 6 & 0.74 & 0.78 \\
2 & phi096 & 10 & 0.84 & 0.86 \\
3 & umc2319 & 11 & 0.70 & 0.73 \\
4 & umc2236 & 7 & 0.65 & 0.69 \\
5 & umc1072 & 7 & 0.73 & 0.76 \\
6 & umc1134 & 8 & 0.54 & 0.55 \\
7 & umc2043 & 9 & 0.83 & 0.85 \\
8 & umc1133 & 11 & 0.81 & 0.83 \\
9 & bnlg1700 & 13 & 0.84 & 0.86 \\
10 & umc1433 & 5 & 0.55 & 0.60 \\
11 & umc1562 & 9 & 0.79 & 0.81 \\
12 & umc2119 & 11 & 0.89 & 0.91 \\
13 & umc1771 & 8 & 0.75 & 0.79 \\
14 & umc1421 & 8 & 0.73 & 0.77 \\
15 & bnlg1496 & 8 & 0.79 & 0.82 \\
16 & umc1058 & 12 & 0.86 & 0.86 \\
17 & umc1019 & 10 & 0.87 & 0.88 \\
18 & umc2038 & 9 & 0.81 & 0.83 \\
19 & umc2313 & 18 & 0.90 & 0.92 \\
20 & umc1595 & 3 & 0.43 & 0.49 \\
\hline & Mean & $\mathbf{9 . 1 5}$ & $\mathbf{0 . 7 5}$ & $\mathbf{0 . 7 8}$ \\
\hline
\end{tabular}

Allele number per locus (A), Expected heterozygosity (He) and polymorphism information content (PIC)

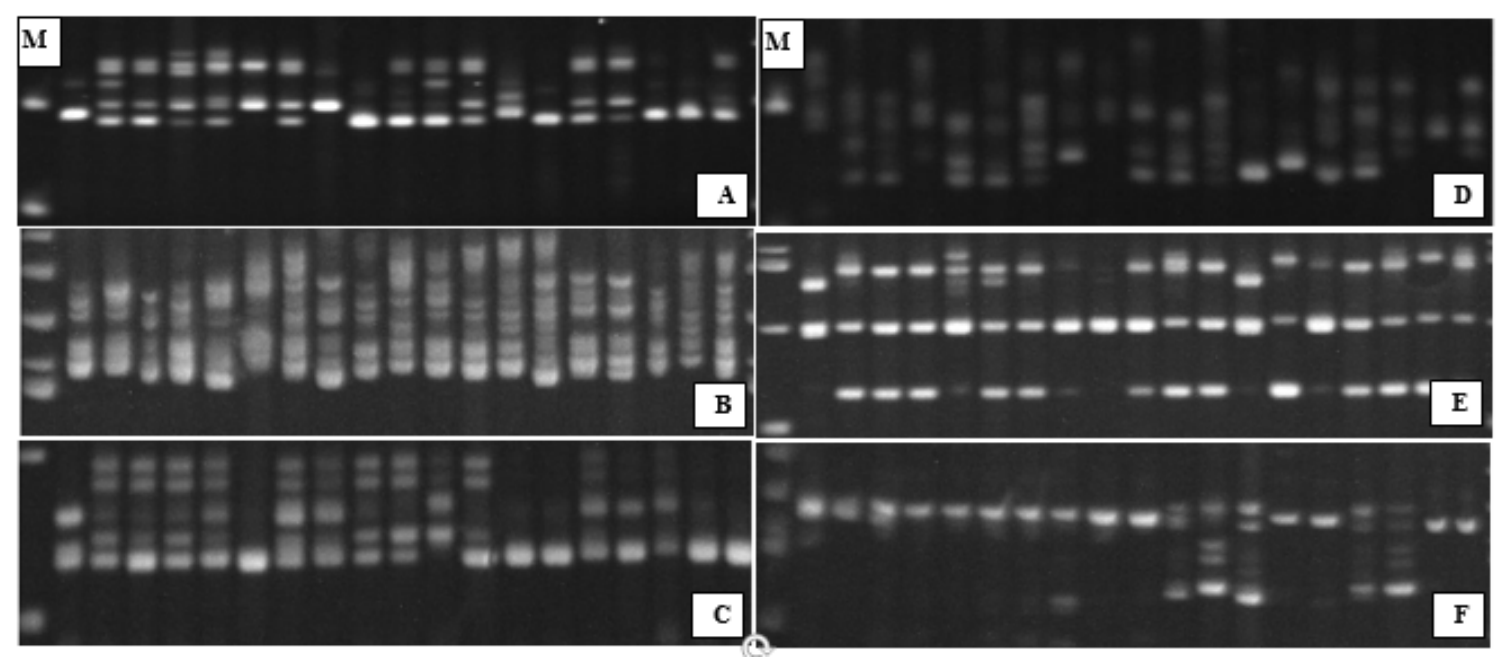

Figure 2: Polyacrylamide Gel Electrophoresis of SSR Allelic Variants in 19 Maize Genotypes. Lanes 2-4; 5-10; 11 15 and 16-20- Farmers' Varieties from Edo, Ekiti, Kwara and IITA Hybrids respectively with six SSR Markers [A (umc1058), B (bnlg1700), C (umc1019), D (umc1771), E (umc2038), and F (phi096)], M- DNA sizing standards 


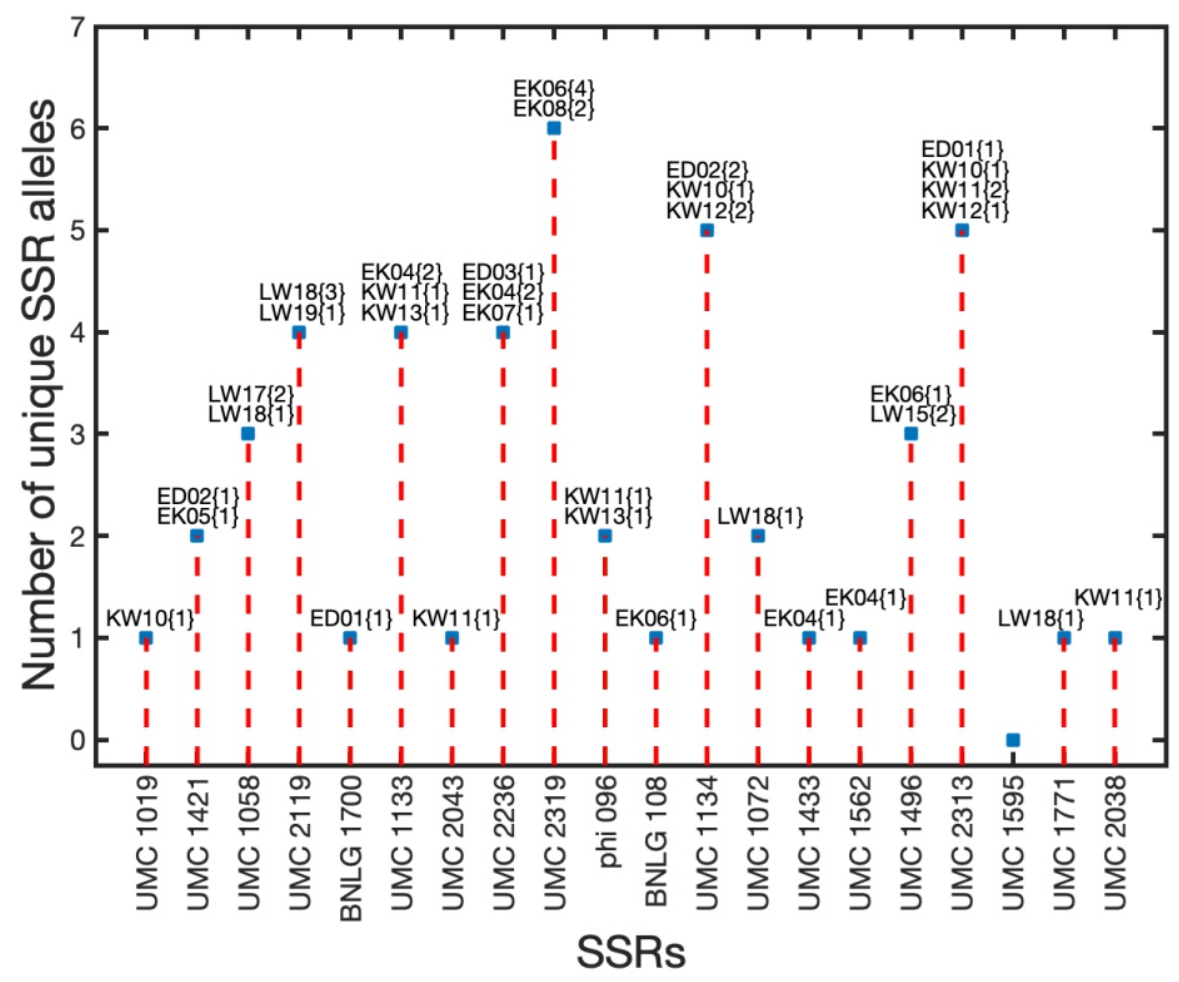

Figure 3: Number of Unique SSR Alleles in the Farmers' Maize Genotypes or IITA Hybrids.

The number in brackets is the number of the unique allele present in each maize genotype for each SSR locus.

Genotypes are labelled according to table 1.

Table 4: Number of SSR Markers based on QTL Type, Average, Minimum, Maximum Number of Alleles among 19 Maize Genotypes

\begin{tabular}{llllll}
\hline QTL names & No. of markers & No. of alleles & Minimum & Maximum & Average \\
\hline Oil content (oilc,qOIL/koc) & 7 & 58 & 6 & 11 & 8.29 \\
Protein content (Proc/qPRO) & 9 & 85 & 5 & 13 & 9.44 \\
Protein and oil contents (qPRO06-01/qOIL06-01) & 4 & 40 & 3 & 18 & 10 \\
\hline
\end{tabular}

Table 5: Sample Size and Measure of Diversity within the Three States and IITA Hybrids based on 20 SSR Loci

\begin{tabular}{lllll}
\hline $\begin{array}{l}\text { States } \\
\text { Hybrids }\end{array}$ & $\begin{array}{l}\text { Sample } \\
\text { size }\end{array}$ & $\begin{array}{l}\text { Number of variable } \\
\text { loci }\end{array}$ & $\begin{array}{l}\text { Average no. Allele/locus } \\
\text { (range) }\end{array}$ & $\begin{array}{l}\text { Number of Polymorphic } \\
\text { loci }\end{array}$ \\
\hline EDO & 3 & 20 & $4(1-7)$ & 16 \\
EKITI & 5 & 20 & $5(2-11)$ & 20 \\
KWARA & 6 & 20 & $6(2-11)$ & 20 \\
IITA & 5 & 20 & $5(1-7)$ & 19 \\
HYBRIDS & 5 & & & \\
\hline
\end{tabular}

Genetic Relationship among the Genotypes

Based on the similarity coefficient data, a dendrogram was constructed using UPGMA to reveal the genetic relationships among the studied maize genotypes. The genetic similarity coefficient ranged from 0.44 to 0.87 , with an average of 0.72 . As presented in figure 4, the maize genotypes can be separated into two distinct groups (Groups I and II) and a singleton. The associations between molecular diversity and the state of the collection of farmers' varieties and the newly developed IITA hybrid was considered substantial. The group I contained 5 varieties, of which 3 were from Edo, and the remaining two from Ekiti and the group II contained 13 maize genotypes but subdivided into two subgroups. The subgroup 1 included four farmers' varieties from Kwara (2) and Ekiti (2) and the remaining 2 were from the IITA. The subgroup 2 was composed of three IITA hybrids only (LW17, LW18 and LW19), forming a distinct group and 4 farmers' varieties from Kwara state. The singleton 
was a farmer's variety from Ekiti (EK06) and was a landrace maize type. The lowest similarity coefficient was observed between LW18 and LW19, and the highest similarity coefficient was found for native maize EK06 and LW18, a hybrid from IITA. The factorial analysis using SSR molecular variation performed on the basis of the similarity coefficient data (Figure 5) is consistent with the dendrogram. It showed the equal distribution of the 19 varieties across the axes. The first axis accounted for 5 varieties from Kwara state and 5 IITA hybrids while 5, 3 and 1 varieties from Ekiti, Edo and Kwara, respectively grouped together in the second axis.

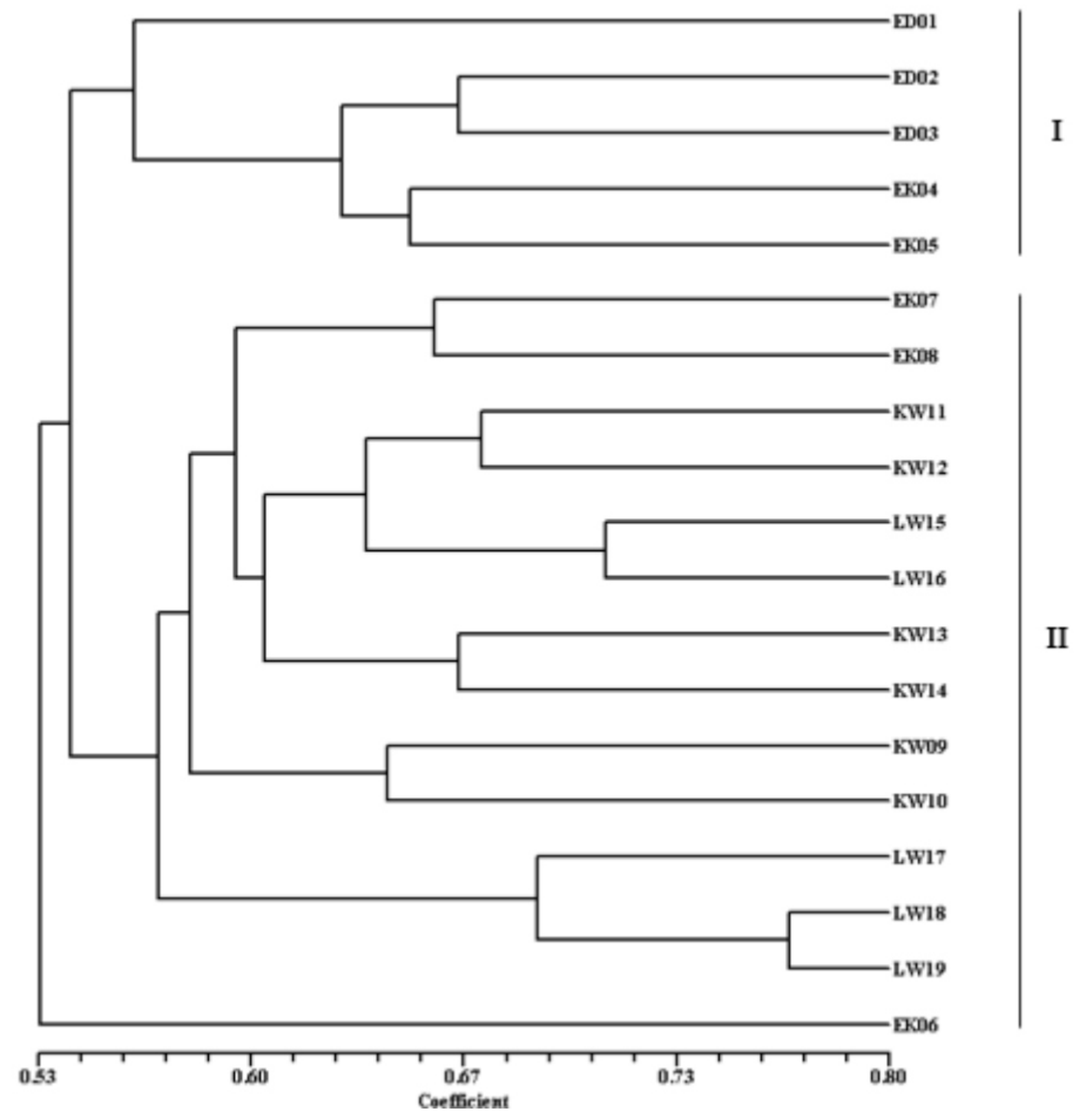

Figure 4: UPGMA Dendrogram indicating Genetic Relationships among 14 Maize Farmers' Varieties collected from Edo, Ekiti and Kwara States in Nigeria and 5 IITA Hybrids 


\section{Factorial analysis: (Axes 1/2)}

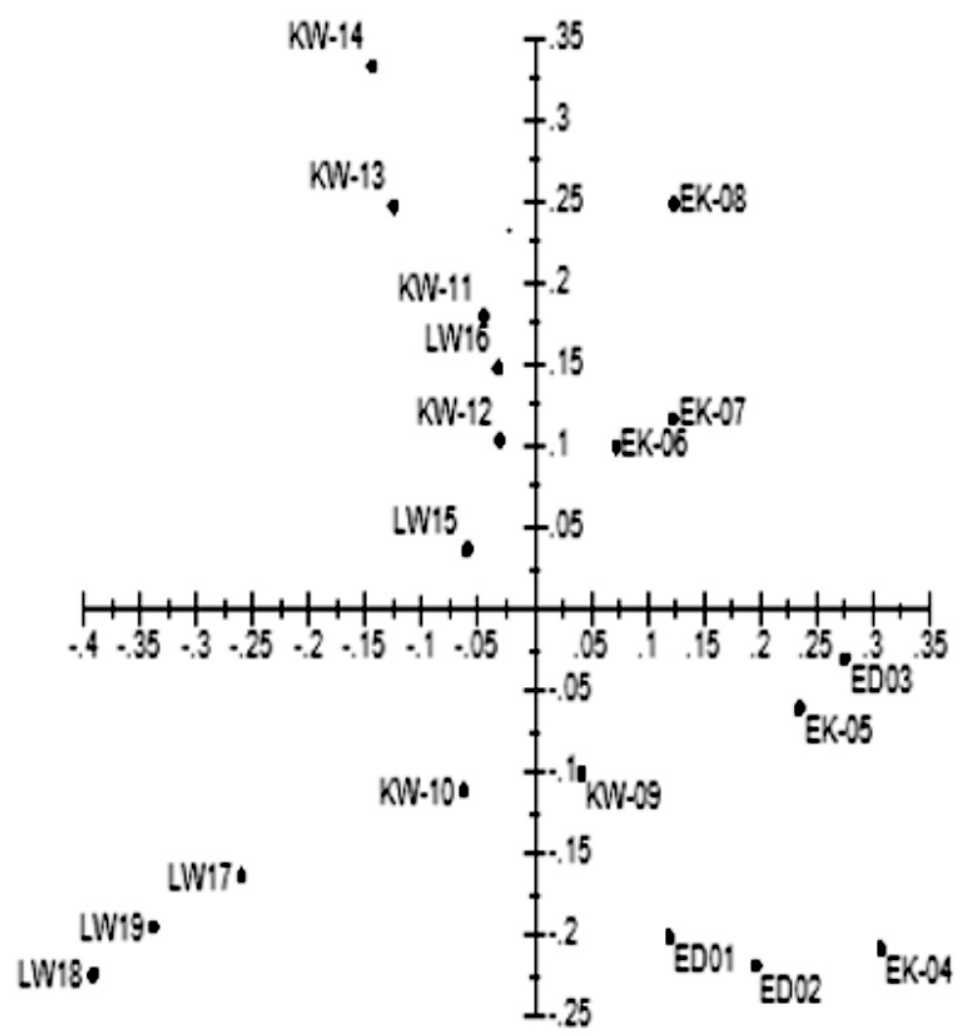

Figure 5: Factorial Plot indicating Genetic Relationships among 14 Maize Farmers' Varieties collected from Edo, Ekiti and Kwara States in Nigeria and 5 IITA Hybrids

Population Structure among the Genotypes The estimated $\log$ probability of the data $(\mathrm{LnP}(\mathrm{D}))$ was performed. The $\mathrm{LnP}(\mathrm{D})$ value of $\mathrm{K}$ ranging from 1 to 2 was calculated by the Structure software and is shown in figure 6 . However, the highest level of structure for the population studied in the present analysis was difficult for determining the optimal $\mathrm{K}$ value, which may have distorted the additional subpopulation. The results implied that the 19 varieties were classified as an admixture and were not assigned to groups and showed approximately
$50 \%$ of the membership to the farmers' and IITA hybrid groups (Figure 7). This revealed that these maize varieties can be grouped into one population, as inferred from the model (Figure 7). The STRUCTURE output was not in agreement with those obtained from the dendrogram and the factorial plot. This clearly reflects the breeding history, since some of these farmers' varieties were produced from the IITA breeding programs and the 19 varieties may possibly have mixed parentage. 


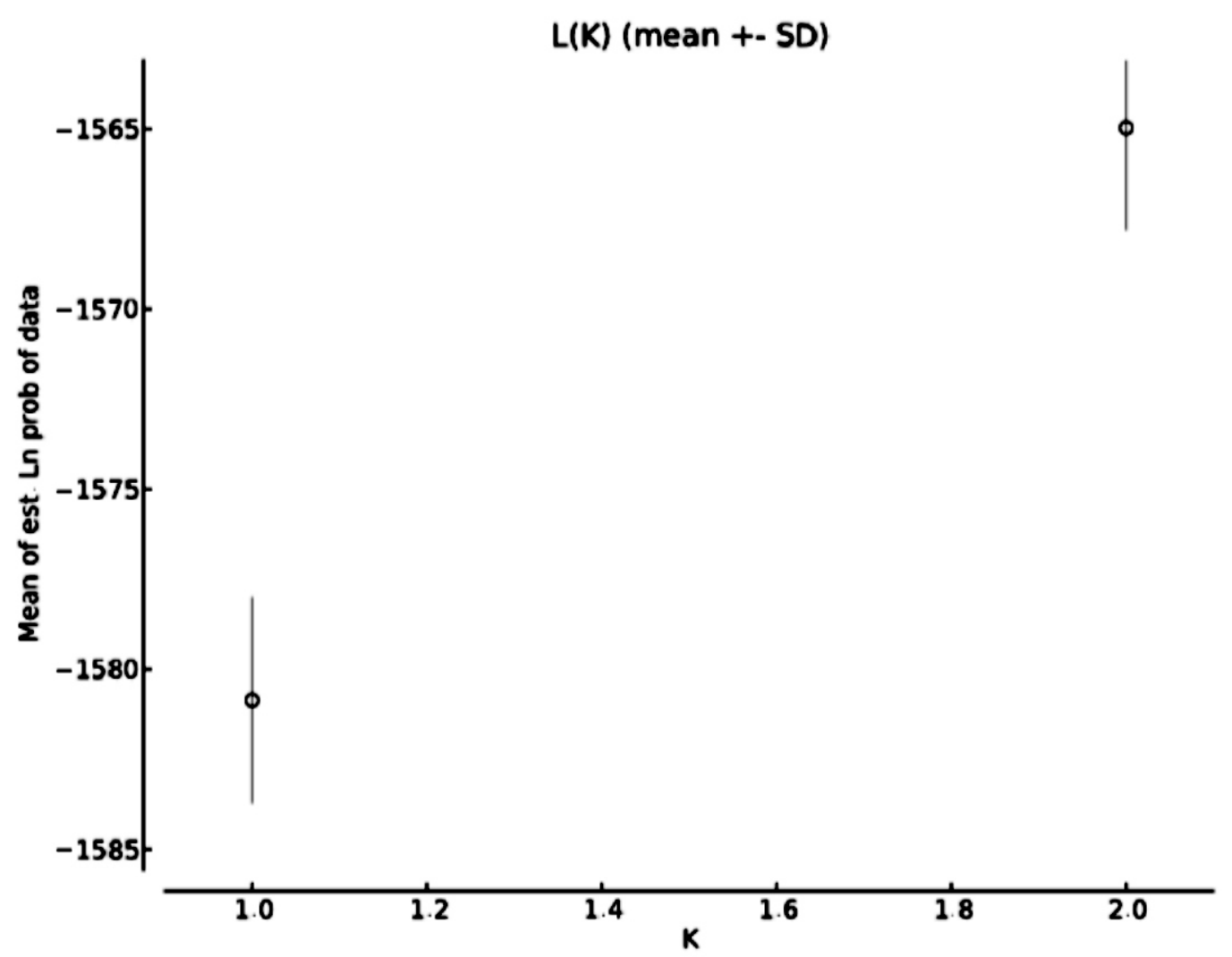

Figure 6: The Plot of LnP (D) in the Population Structure Analysis.

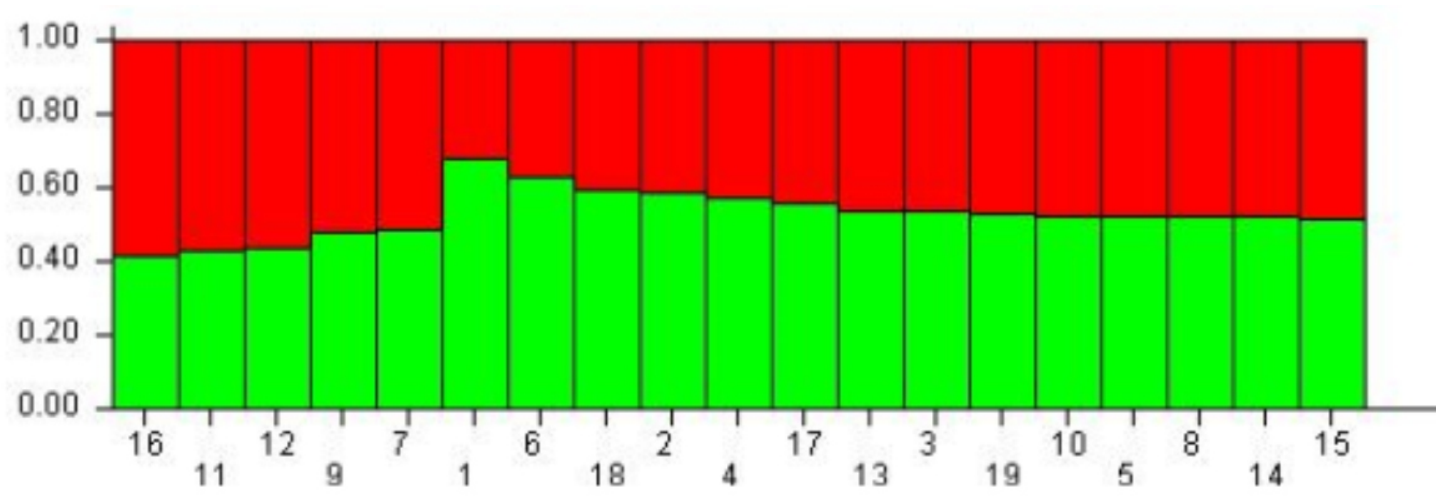

Figure 7: The Estimated Population Structure Analysis showing an Admixture of Alleles in the 19 Maize Varieties based on STRUCTURE Analysis. A vertical bar represents an individual. The two colours in a bar indicate individual estimated membership of each K group

\section{DISCUSSION}

Genetic diversity and population structure analyses are important components of any maize breeding and seed conservation program. SSR markers are among the most successfully used molecular markers for many studies such as genetic diversity, population structure and cultivar identification in maize (Inghelandt et al., 2010). In this study, the extent and pattern of genetic variation existing among 14 maize farmers' varieties collected from Edo, Ekiti and Kwara states in Nigeria were evaluated and their genetic relationships with five newly developed IITA hybrids were assessed using 20 SSR markers. The SSR markers used in the study were markers or flanking markers of previously mapped QTLs and located in chromosomes for the oil and protein or oil/protein contents ((Mangolin et al., 2004; Zhang et al., 2007; Yang et al., 2016) which enabled the detection of the genetic relationships 
among maize farmers' varieties collected from three states in Nigeria and the five newly developed from IITA.

The mean number of alleles (9.15) observed in this study was higher than that reported by Yao et al. (2007) and Nyaligwa et al. (2015) who reported mean allele of 6.1 and 4.7 using 54, and 79 maize collections with 42 and 30 SSR markers, respectively. On the other hand, Lia et al. (2009) and Meriem et al. (2018) detected a high mean number of allele per locus (10.2) and (10.3) among maize landraces (147) from Northwestern Argentina and Algerian maize collection landraces (47) both using 18 SSR, respectively. The mean number of alleles observed per marker is dependent on genetic diversity in the collections, sample size, SSR primer pairs used for genotyping, gene flow occurring among maize populations and the sensitivity of the genotyping method. The mean PIC value for SSR markers was equally high (0.75) compared to previous studies ( $\mathrm{Sa}$ et al., 2018; Adeyemo et al., 2018). The detection of the alleles and high PIC values in this present study could have been attributed to the high discriminating capacity of the set of SSR markers linked to kernel oil and protein QTLs or both among the 19 genotypes. This further showed that the maize genotypes studied may have high genetic variations for the oil and protein contents. A significant amount of unique alleles was present among the maize genotypes, suggesting that each genotype may still possess unique genetic characteristics. The number of private alleles may be as a result of the sample size (Szpiech et al., 2008), however, in this study, we had a relatively small number of samples producing high number of unique alleles, suggesting that the genetic composition of the germplasm used in the present study could also have contributed to the number of unique alleles. Moreover, the presence of a high number of alleles per SSR produced may have contributed to the detection of unique alleles, indicating overall genetic diversity of the current set, which could provide important genetic resources for maize breeding programs.

In this study, the characterisation of the maize genotypes collected from Edo, Ekiti and Kwara states and IITA hybrid revealed that there were genetic variations among the maize germplasm examined. The grouping of varieties from these states close to each other may thus be indicative that the genetic diversity may be linked probably to the similarity in the environmental conditions (soil types and rainfall), agricultural practices and agro-ecosystems of the state. Based on the dendrogram and factorial analyses of the three states, Edo, Ekiti and Kwara in this study, the farmers' varieties from Edo were more similar to those from Ekiti than from Kwara. The dendrogram analysis based on the farmers' varieties and the IITA hybrids indicated that IITA hybrids grouped closely with all the varieties from Kwara state. This shows genetic relatedness and more impact on the use of modern varieties by the farmers in Kwara state. This can be explained by the fact that the new improved IITA hybrids may have been derived from some locally adapted maize genotypes and/or may be similar to the modern varieties used by the present farmers.

Based on individual farmers' varieties collected from each state, the Edo, Ekiti and Kwara grouped within each state and most of the IITA showed some genetic relatedness. This grouping may be attributed to a certain level of adaptive characteristics of the varieties to each state. EK06 represented an exception based on the dendrogram, showing that it had a unique genetic background. However, based on the factorial analysis, EK06 grouped with EK07. Thus it would be valuable for the IITA maize breeding program to consider the use of EK06 for future work to develop broader genetic diversity. During the collection of the farmers' varieties, it was noticed that majority of the farmers have preferential selection for modern maize varieties having characteristics such as plants smaller in stature with a shorter growing period and yellow kernel colour, which has been the situation for a long time now (Salami et al., 2007).

Out of the low number of landraces (3) collected from farmers, KW09 and KW10 grouped closely, although were collected from two different towns. The grouping together of these varieties confirms that they are landraces based on the SSR markers. While the remaining one (EK06) landrace is the only genotype in the whole collection that stood separately. The analysis of genetic diversity of the 
maize genotypes grown by small scale farmers may yield important insights for their genetic conservation as it has been revealed in the present study (Guarino et al., 2002). It was observed that there is a decrease in maize landrace population in the three states.

A population structure analysis based on STRUCTURE was also inferred in the study to correctly detect the genetic stratification based on genetic relatedness among samples (Falush et al., 2003). Here, it showed no clear grouping of populations among the collected farmers' genotypes and the IITA hybrids, suggesting that a strong genetic admixture was present among the accessions and no pure line was detected. This makes no consistency between the groups obtained from dendrogram and factorial analyses. The mixture could be due to the result of the breeding history of sharing one gene pool, which can have large effects on the diversity structure in the current study. Furthermore, another possible cause of admixture could be the partial sampling of individuals (Evanno et al., 2005). A similar pattern was obtained in previous studies (Xia et al., 2005; Semagn et al., 2014; Meriem et al., 2018). They observed no clear genetic differentiation among the groups in the context of breeding programs, mega-environments, and specific agronomic traits, phenotypes, environmental adaptation, grain colour or type, heterotic groups and geographical origins.

This study helped to show that farmers had access to more improved varieties and have interests in their use. This study has reflected the impact of modern and improved varieties on the dwindling conservation of the landraces among the farmers. It has been well reported that landraces are gradually disappearing because of a large concentration on the use of modern varieties (van Etten etal., 2008).

In conclusion, the study using SSR markers or flanking markers of previously mapped QTLs for oil and protein or oil/protein contents has revealed considerable levels of genetic diversity in the farmers' varieties and their genetic relationship with the IITA maize hybrids. The study also demonstrated the impact of improved varieties on the genetic diversity and the lack of preservation of landraces among the farmers. The information obtained from the study may form the basis for maize breeding and conservation programs in the future.

\section{ACKNOWLEDGMENTS}

This research was supported by the Tertiary Education Trust fund (TETFUND) Grant, Nigeria (CRC/TETFUND/NO2017/07)221-6$00)$.

Conflict of Interest: None declared.

\section{REFERENCES}

Abdulmalik, R. O., Menkir, A., Meseka, S. K., Unachukwu, N., Ado, S. G., Olarewaju, J. D. and Gedil, M. 2017. Genetic gains in grain yield of a maize population improved through marker assisted recurrent selection under stress and nonstress conditions in West Africa. Frontiers in Plant Science. 8: 841. doi: 10.3389/fpls.2017.00841

Adeyemo, O. and Omidiji, O. 2014. SSR-based and carotenoid diversity assessment of tropical yellow endosperm maize inbred lines. Plant Genetic Resources: Characterization and Utilization. 12(1): 67-73.

Adeyemo, O.A., Bhadmus, O.A., Adebesin, O.A and Okinedo. U. E. 2018. Assessment of genetic diversity among selected maize landraces and hybrids using SSR markers linked to QTLs for drought and nitrogen tolerance. Nigerian Journal of Genetics. 32(1):182-190.

Bedoya, C.A., Dreisigacker, S., Hearne, S., Franco, J., Mir, C., Prasanna, B. M., Taba, S., Charcosset, A. and Warburton, M.L. 2017. Genetic diversity and population structure of native maize populations in Latin America and the Caribbean. PLOS ONE 12(4). e0173488. https://doi.org /10.1371/journal.pone.0173488.

Doyle, J.J. and Doyle, J.L. (1987). A rapid DNA isolation procedure for small quantities of fresh leaf tissue. Phytochemical Bulletin. 19:11-15.

Earl, D.A. and von Holdt, B.M. 2012. Structure harvester: a website and program for 
visualizing structure output and implementing the Evanno method. Conserv. Genet. Res. 4:359-361.

Evanno, G., Regnaut, S. and Goudet, J. 2005. Detecting the number of clusters of individuals using the software structure: a simulation study. Mol. Eco. 114:2611-2620. https://doi.org/10.1111/j.1365294x.200 $5.02553 x$.

Falush, D., Stephen, M. and Pritchard, J.K. 2003. Inference of population structure: extensions to linked loci and correlated allele frequencies. Genetics, 164:15671587.

Guarino, L., Jarvis, A., Hijmans, R.J. and Maxted, N. 2002. Geographic Information Systems (GIS) and the conservation and use of plant genetic resources. In: Engels J.M.M., Ramanatha R. V., Brown A.H.D. and Jacson, M.T. (eds). Managing plant genetic diversity. International Plant Genetic Resources Institute (IPGRI) Rome, Italy. pp 387-404.

Inghelandt, D, V. Melchinger, A. Lebreton, E. C. and Stich, B. 2010. Population structure and genetic diversity in a commercial maize breeding program assessed with SSR and SNP markers. Theor. Appl. Genet., 120(7): 1289-1299.

Lia, V.V., Poggie, L. and Confalonieri, V.A. 2009. Microsatellite variation in maize landraces from Northwestern Argentina: Genetic diversity, population structure and racial affiliations. Theor. Appl. Genet., 119:1053-1067. DOI 10.1007/s00122009-1108-0.

Mangolin, C.A., de Souza, C.L. Jr., Garcia, A.A.F., Garcia, A.F., Sibov, S.T. and de Souza, A.P. 2004. Mapping QTLs for kernel oil content in a tropical maize population. Euphytica, 137: 251-259.

Meriem, A. M., Lupini, A., Mauceri, A., \& Abdelkader, M., Khelifi, L. and Sunseri, F. 2018. Genetic variation and structure of maize populations from Saoura and Gourara oasis in Algerian Sahara. BMC Genetics, 19. 10.1186/s12863-018-06552.

Nyaligwa, L., Hussein, S., Amelework, B. and Ghebrehiwot, H. 2015. Genetic diversity analysis of elite maize inbred lines of diverse sources using SSR markers. Maydica. 60-M29.

Perrier, X. and Jacquemoud-Collet, J. P. 2006. http://Darwin.cirad.fr/. Accessed $2^{\text {nd }}$ February, 2019

Peakall, R. and Smouse, P.E. 2006. GenAIEx V5: Genetic Analysis in Excel. Populations Genetic Software for Teaching and Research. Molecular Ecology Notes, 6: 288-295.

Pritchard, J.K., Stephens, M. and Donnelly, P. 2000. Inference of population structure using multilocus genotype data. Genetics, 155: 945-59.

Rohlf, F.J. 1993. NTSYS-pc, numerical taxonomy and multivariate analysis system. Exeter software, New York.

Rogers, J.S. 1972. Measures of genetic similarity and genetic distance. Stud Genet VII Univ Tex Publ 7213:145-153.

Sa, K. J., Hong, T. K. and Lee, J.K. 2018. Genetic Diversity and Association Analyses of Canadian Maize Inbred Lines with Agronomic Traits and Simple Sequence Repeat Markers Plant Breed. Biotech., 6(2):159-169.

Salami, A.E., Adegoke, S.A.O. and Adegbite, O.A. 2007. Genetic Variability among Maize Cultivars Grown in Ekiti-State, Nigeria. Middle-East Journal of Scientific Research. 2 (1):09-13.

Semagn, K., Magorokosho, C. Ogugo, V. Makumbi, D. and. Warburton, M. L. 2014. Genetic relationships and structure among open-pollinated maize varieties adapted to eastern and southern Africa using microsatellite markers. Molecular Breeding. pp. 1-13. (doi:10.1007/s11032014-0126-z).

Szpiech, Z.A., Jakobsson, M. and Rosenberg, N.A. 2008. ADZE: a rarefaction approach for counting alleles private to combinations of populations. Bioinformatics. 24:2498-2504.

van Etten, J., Fuentes López, M.R., Molina Monterroso, L.G. and Samayoa, K. M. P. 2008. Genetic diversity of maize (Zea mays L. ssp. mays) in communities of the western highlands of Guatemala 
Adeyemo and Omidiji: Genetic Diversity and Population Structure of Farmers' Maize

geographical patterns and processes. Genet. Resour. Crop Evol., 55(2): 303317.

Warburton, M.L., Reif, J.C., Frisch, M., Bohn, M., Bedoya, C., Xia, X.C., Crossa, J., Franco, J., Hoisington, K. D., Pixley., S., Taba, S. and Melchinger A. E. 2008. Genetic diversity in CIMMYT nontemperate maize germplasm: Landraces, open pollinated varieties, and inbred lines. Crop Sci., 48(2): 617-624.

Xia, C., Reif, J.C., Melchinger, A.E., Frisch, M., Hoisington, D.A. and Beck, D. 2005. Genetic diversity among CIMMYT maize inbred lines investigated with SSR markers: II. Subtropical, tropical mid altitude, and highland maize inbred lines and their relationships with elite U.S. and European maize. CropSci., 45: 2573-82.

Yang, Z., Li, X., Zhang, N., Zhang, Y.N., Jiang, H.W. Gao, J., Kuai, B.K., Ding, Y.L. and Huang, X.Q. 2016. Detection of quantitative trait loci for kernel oil and protein concentration in a B73 and
Zheng58 maize cross. Genetics and Molecular Research.15 (3):1-10.

Yao, Q., Yang K.., Pan G. and Rong, T. 2007. Genetic Diversity of Maize (Zea mays L.) Landraces from Southwest China Based on SSR Data. Journal of Genetics and Genomics.34(9): 851-860.

Zhang, J., Lu, X.Q., Song, X.F., Yan, J.B., Song, T.M., Dai, J.R., Rocheford, T. and Li, J.S. 2007. Mapping quantitative trait loci for oil, starch, and protein concentrations in grain with high-oil maize by SSR markers. Euphytica, 162 (3):335-34.

Zhi-zhai, L., Rong-hua, G., Jiu-ran, Z., Yi-lin, C., Feng-ge, W., Mo-ju, C., Ronghuan, W., Yun-su, S., Yan-chun, S., Tian-yu, W. and Yu, L. 2010. Analysis of Genetic Diversity and Population Structure of Maize Landraces from the South Maize Region of China. Agricultural Sciences in China. 9(9): 1251-1262. 